\title{
CARACTERIZAÇÃO MORFOLÓGICA E GERMINAÇÃO DE SEMENTES DE Curitiba prismatica (D. Legrand) Salywon \& Landrum ${ }^{1}$
}

\author{
SUELEN SANTOS REGO², NELSON LUIZ COSMO ${ }^{3}$, ALESSANDRA MARA GOGOSZ $^{4}$, \\ YOSHIKO SAITO KUNIYOSHI ${ }^{5}$, ANTONIO CARLOS NOGUEIRA ${ }^{6}$
}

\begin{abstract}
RESUMO - Este trabalho objetivou caracterizar morfologicamente as sementes e o desenvolvimento da plântula de Curitiba prismatica e verificar as melhores temperaturas, substratos e condição de luz para a germinação das sementes. A semente caracteriza-se como exalbuminosa e possui forma elíptica espiralada com tegumento coriáceo, de coloração castanho-escura. O embrião é descrito como cotiledonar pimentóide, axial, carnoso e cilíndrico, curvado em forma de "C $\mathrm{C}$ " e de coloração branca. O desenvolvimento da plântula se inicia com a abertura do opérculo e uma pequena expansão do hipocótilo nesta região. Após esta expansão, ocorre o desenvolvimento de pêlos na base do hipocótilo, e a emissão da radícula por volta do 180 dia, sendo que aos 45 dias já se tem a plântula propriamente dita, caracterizada pelo surgimento dos eofilos. Os melhores valores para a porcentagem, tempo médio e velocidade de germinação das sementes de C. prismatica foram obtidos com a temperatura $25^{\circ} \mathrm{C}$, nos substratos papel toalha e areia. A espécie pode ser classificada como fotoblástica positiva preferencial.
\end{abstract}

Termos para indexação: Myrtaceae, substrato, temperatura, luz.

\author{
SEED MORPHOLOGY AND GERMINATION OF \\ Curitiba prismatica (D. Legrand) Salywon \& Landrum
}

\begin{abstract}
This study aimed to characterize the seed, and seedling morphology and development of $C$. prismatica and to identify the best temperature, substrate and light conditions for germination. The seed is characterized as exalbuminous and has a spiral, elliptical shape, with a coriaceous, dark-brown tegument. The embryo is described as cotyledonary pimentoid, axial, meaty and cylindrical, curved into a " $\mathrm{C}$ " and is white. Seedling development begins with the operculum opening and a small expansion of hypocotyl in this region. After this expansion, hairs develop at the base of the hypocotyl and the emission of the radicle occurs around the $18^{\text {th }}$ day, and by 45 days the seedling has already developed the protophyll. The highest values for percentage, mean time and germination speed of $C$. prismatica seeds were obtained at $25^{\circ} \mathrm{C}$, using a paper towel substrate and sand. The species can be classified as being preferentially positively photoblastic.
\end{abstract}

Index terms: Myrtaceae, substrate, temperature, light.

\footnotetext{
${ }^{1}$ Submetido em 13/04/11. Aceito para publicação em 04/05/11.

${ }^{2}$ Bióloga, pós-graduanda do Departamento de Eng. Florestal, UFPR, bolsista REUNI, suelen_srego@yahoo.com.br.

${ }^{3}$ Eng. Florestal, pós-graduando em Engenharia Florestal, UFPR, bolsista CNPQ, ncosmo@gmail.com

${ }^{4}$ Bióloga, pós-graduanda do Departamento de Ecologia, UFPR, bolsista
}

REUNI, alegogosz@gmail.com

${ }^{5}$ Naturalista., Dra., Professora Sênior, Departamento de Ciências Florestais, UFPR, yoshiko@ufpr.br.

${ }^{6}$ Eng. Florestal, Dr., Professor Associado II, Departamento de Ciências Florestais, Universidade Federal do Paraná (UFPR), CEP: 80210-170. Curitiba, nogueira@ufpr.br. 


\section{INTRODUÇÃO}

Com a exploração dos recursos naturais, principalmente das espécies arbóreas, visando o uso da madeira e a abertura de novas áreas para a agricultura, as florestas nativas encontram-se fragmentadas e reduzidas a porções muito pequenas em relação às suas áreas originais. Desta forma, para atender aos programas de recuperação ambiental, a demanda por mudas de espécies florestais nativas tem sido crescente. Visto que a grande maioria destas é propagada por sementes, o sucesso na formação das mudas depende do conhecimento sobre o processo germinativo de cada espécie e da qualidade da semente utilizada (Rego et al., 2009). No entanto, para uma grande parte das espécies nativas não se tem metodologia padronizada para o teste de germinação.

A temperatura é um dos fatores que mais influenciam sobre o processo germinativo, tanto na porcentagem como na velocidade de germinação, regulando a velocidade de absorção de água e as reações bioquímicas que determinam todo o processo (Carvalho e Nakagawa, 1983). As sementes possuem comportamento bastante variável frente ao fator temperatura, não havendo uma temperatura ótima e uniforme de germinação para todas as espécies (Borges e Rena, 1993). No entanto, estes autores indicam a faixa de 20 a $30{ }^{\circ} \mathrm{C}$ como adequada para a germinação de um grande número de espécies subtropicais e tropicais, e Piña-Rodrigues et al. (2004) indicam a faixa entre $15{ }^{\circ} \mathrm{C}$ e $30{ }^{\circ} \mathrm{C}$.

O substrato em que a semente é colocada para germinar também exerce importante função na germinação, mantendo a umidade e preservando as condições ideais para que esta ocorra (Piña-Rodrigues e Vieira, 1988). Na escolha do substrato deve ser levado em consideração o tamanho da semente, sua exigência com relação á quantidade de água, sua sensibilidade ou não à luz e a facilidade que o mesmo oferece para a realização das contagens e para a avaliação das plântulas (Figliolia et al., 1993). Os tipos de substratos mais utilizados, descritos e prescritos pelas Regras para Análise de Sementes (Brasil, 2009), são: papel toalha, papel filtro, papel mataborrão e areia. Para as espécies florestais nativas, poucas recomendações e prescrições existem e outros tipos de substratos têm sido testados, principalmente a vermiculita (Figliolia et al., 1993).

A luz é outro fator que fortemente regula o processo germinativo, pois algumas espécies germinam somente no escuro, e outras só na presença de luz(Carvalho e Nakagawa,
1983). De acordo com as respostas das sementes à luz, elas podem ser classificadas em fotoblásticas positivas (germinação promovida pela luz), fotoblásticas negativas (germinação promovida pelo escuro) e não fotoblásticas, que são indiferentes ou insensíveis à luz (Marcos Filho, 2005). No entanto, de acordo com Klein e Felippe (1991), o fotoblastismo positivo nem sempre é absoluto, pois muitas espécies que se comportam como fotoblásticas positivas apresentam pelo menos alguma germinação no escuro. Em outros casos, embora estatisticamente a espécie possa ser considerada fotoblástica positiva, este caráter é apenas quantitativo, uma vez que tanto na presença como na ausência de luz ocorre considerável germinação de suas sementes, sendo estas espécies classificadas como fotoblásticas preferenciais. Seguindo o mesmo raciocínio, Gui Ferreira et al. (2001) classificaram as sementes em afotoblásticas (indiferentes), fotoblásticas positivas relativas (percentuais de germinação mais altos na luz), fotoblásticas positivas (percentual de germinação na luz mais que o dobro do percentual no escuro) e fotoblástica negativa relativa (percentuais de germinação mais altos no escuro).

Outro campo pouco estudado para as espécies florestais, e de fundamental importância para o conhecimento do processo germinativo das sementes é a morfologia, pois a partir de conhecimentos sobre as estruturas da semente podem-se obter indicações não apenas sobre germinação, mas sobre armazenamento, viabilidade e métodos de semeadura (Kuniyoshi, 1983). Para a família Myrtaceae, a caracterização morfológica torna-se ainda mais necessária, principalmente as características do embrião, pois são de grande importância taxonômica e têm servido de base para a classificação da tribo Myrteae, que compreende quase todas as espécies sul-americanas da família (Landrum e Kawasaki, 1997; Barroso et al., 1999). De acordo com Barroso (1984), as espécies americanas de Myrtaceae assemelham-se muito na maioria dos caracteres, tornandose muito difícil o trabalho de identificá-las e classificálas, sendo as características do embrião, muitas vezes o diferencial.

Curitiba prismatica (D. Legrand) Salywon \& Landrum inicialmente classificada como Eugenia prismatica (D. Legrand) foi recentemente transferida para um novo gênero criado para acomodar esta espécie. Trata-se de uma homenagem à cidade de Curitiba - PR, região em que o gênero pode ser encontrado crescendo em parques e remanescentes florestais (Salywon e Landrum, 2007).

Curitiba prismatica é uma espécie arbórea que pode 
atingir de 2 a 12 metros de altura, conhecida popularmente como guamirim, cambuí ou murta. Floresce durante os meses de dezembro a fevereiro e os frutos amadurecem quase simultaneamente, de janeiro a março. Frutifica todos os anos com produção abundante de sementes viáveis, dispersadas pela avifauna (Lorenzi, 1998). Ocorre principalmente nas orlas e no interior de capões da Foresta Ombrófila Mista. No estado do Paraná é encontrada no primeiro e no segundo planalto (Legrand e Klein, 1969; Lorenzi, 1998; Salywon e Landrum, 2007). A madeira da espécie é empregada localmente para uso interno em construção civil, para obras externas como moirões, e para lenha e carvão. Por seu aspecto ornamental, é recomendada para o paisagismo, principalmente na arborização urbana, e para a composição de plantios heterogêneos destinados à recuperação de áreas degradadas (Lorenzi, 1998).

Com base nas informações citadas, este trabalho objetivou caracterizar morfologicamente as sementes e o desenvolvimento da plântula de Curitiba prismatica e verificar as melhores temperaturas, substratos e condições de luz para a germinação.

\section{MATERIAL E MÉTODOS}

Os frutos de Curitiba. prismatica foram coletados de seis matrizes localizadas em remanescente de Floresta Ombrófila Mista no município de São Mateus do SulPR, no mês de abril de 2008. A extração das sementes foi realizada manualmente por meio da maceração e lavagem dos frutos em água corrente, sendo as sementes deixadas secar a sombra em ambiente de laboratório durante 24 horas.

Caracterização morfológica da semente: para descrever e ilustrar morfologicamente, foram utilizadas 100 sementes aleatoriamente, e as medidas de comprimento, largura e espessura obtidas com auxílio de um paquímetro. As sementes foram caracterizadas quanto à cor, textura, consistência, forma, posição do hilo e da micrópila, presença ou ausência de endosperma, e se presente, o tipo e a cor. Foram considerados também o tipo, a posição e a forma do embrião, a forma e consistência dos cotilédones e a posição do eixo hipocótilo-radícula, sendo as características morfológicas relevantes da semente ilustradas e descritas com base nos trabalhos de (Kuniyoshi 1983 e Barroso et al.,1999).

Caracterização morfológica do desenvolvimento da plântula: para o acompanhamento do desenvolvimento da plântula, 100 sementes foram colocadas para germinar sobre três folhas de papel toalha umedecidas com água destilada em gerbox, na temperatura de $25{ }^{\circ} \mathrm{C}$ sob luz constante, e 50 sementes em bandejas plásticas, sobre vermiculita. Para a caracterização morfológica das plântulas, foram realizadas ilustrações das características da raiz, do hipocótilo, do epicótilo, dos cotilédones e dos eofilos, conforme (Vidal e Vidal 2003).

Análises físicas das sementes: foram realizados testes para obter uma estimativa do peso de mil sementes, do número de sementes por quilo e do grau de umidade, conforme as Regras para Análise de Sementes (Brasil, 2009). Para o peso de mil sementes foram utilizadas oito amostras de 100 sementes e para o grau de umidade três repetições de um grama, utilizando-se o método de estufa a $105 \pm 3{ }^{\circ} \mathrm{C}$ por 24 horas.

Germinação das sementes em diferentes temperaturas e substratos: no teste de germinação foram utilizados os substratos rolo de papel, papel toalha e areia, e as temperaturas de $20{ }^{\circ} \mathrm{C}, 25{ }^{\circ} \mathrm{C}$ e $30{ }^{\circ} \mathrm{C}$, com quatro repetições de 40 sementes para cada tratamento. O substrato papel toalha foi previamente esterilizado em estufa regulada a $105{ }^{\circ} \mathrm{C}$ durante 24 horas e o substrato areia a $200{ }^{\circ} \mathrm{C}$ durante 2 horas. Para o substrato papel toalha foram utilizadas três folhas umedecidas com água destilada. Para o substrato areia foram selecionados os grãos de granulometria média, passando a areia em duas peneiras $(1 \mathrm{~mm}$ e $0,35 \mathrm{~mm})$. Foram selecionados $100 \mathrm{~g}$ de areia e adicionado $20 \mathrm{~mL}$ de água destilada, que correspondeu à capacidade de campo do substrato, e para o substrato rolo de papel foram utilizadas quatro folhas umedecidas com água destilada, sendo as sementes distribuídas sobre duas folhas e recobertas com outras duas folhas, formando os rolos. As sementes foram colocadas em germinadores Biomatic sob luz branca constante.

Germinação das sementes em diferentes condições de luz: para testar o efeito da luz na germinação das sementes foram utilizados gerboxs transparentes para a presença de luz e gerboxs pintados com tinta acrílica preta envoltos com papel alumínio para a ausência de luz. Foram colocadas quatro repetições de 40 sementes sob três folhas de papel toalha umedecidas com água destilada, e estes transferidos para um germinador regulado à temperatura de $25{ }^{\circ} \mathrm{C}$ sob lâmpadas fluorescentes. As avaliações foram realizadas em ambiente escuro sob uma lâmpada de luz verde de segurança, confeccionada conforme Usberti, (1979): lâmpada fluorescente de $20 \mathrm{~W}$ recoberta com papel celofane verde, cujo espectro dá um pico a $525 \mathrm{~nm}$, de $0,02 \mu \mathrm{w} / \mathrm{cm}^{2} . \mathrm{nm}$. 
Foram consideradas sementes germinadas quando apresentaram protrusão da radícula, com no mínimo 2 $\mathrm{mm}$, sendo avaliados a porcentagem, o tempo médio (TM) (Laboriau, 1983) e o índice de velocidade de germinação (IVG) (Maguire, 1962). A influência da temperatura e do substrato foi analisada em blocos ao acaso com repetições e as médias comparadas entre si pelo teste de Tukey em $5 \%$ de probabilidade. Os dados do experimento com diferentes condições de luz (luz e escuro) foram submetidos aos testes $\mathrm{F}$ e t em 5\% de probabilidade.

\section{RESULTADOS E DISCUSSÃO}

Caracterização morfológica da semente: exalbuminosa, com forma elíptica espiralada, ápice e base arredondados (Figura 1-A), apresentando as seguintes dimensões: comprimento médio de $3,3 \mathrm{~mm}$, variando de 2,5 a 4,4 mm; largura média de 2,5 $\mathrm{mm}$, variando de 2,0 a 3,1 $\mathrm{mm}$ e espessura média de $1,1 \mathrm{~mm}$, variando de 0,9 a
$1,5 \mathrm{~mm}$. A semente possui tegumento coriáceo, castanhoescuro, com a região central da semente mais clara, e um opérculo na região da micrópila (opérculo micropilar) (Figura 1-C). Hilo visível sob a forma de um orifício na região ventral da semente (Figura 1-B). Embrião do tipo cotiledonar (distinguem-se o eixo hipocótilo-radícula e os paracotilédones), axial, carnoso e cilíndrico, curvado em forma de "C", e de coloração branca. Nestas sementes o embrião passa a ocupar toda a cavidade da semente (Souza, 2006). Hipocótilo cilíndrico, bem desenvolvido, cerca de três vezes maior que os paracotilédones, sendo estes diminutos, plano-convexos, com diferenciação pouco nítida em relação ao eixo hipocótilo-radícula (Figura 1-D). De acordo com a classificação de Barroso et al. (1999), o embrião de C. prismatica é do tipo pimentóide. Santos et al. (2004) e Rego (2010) verificaram o mesmo tipo de embrião para Campomanesia guazumifolia, Campomanesia xanthocarpa, Psidium cattleyanum, e Blepharocalyx salicifolius.
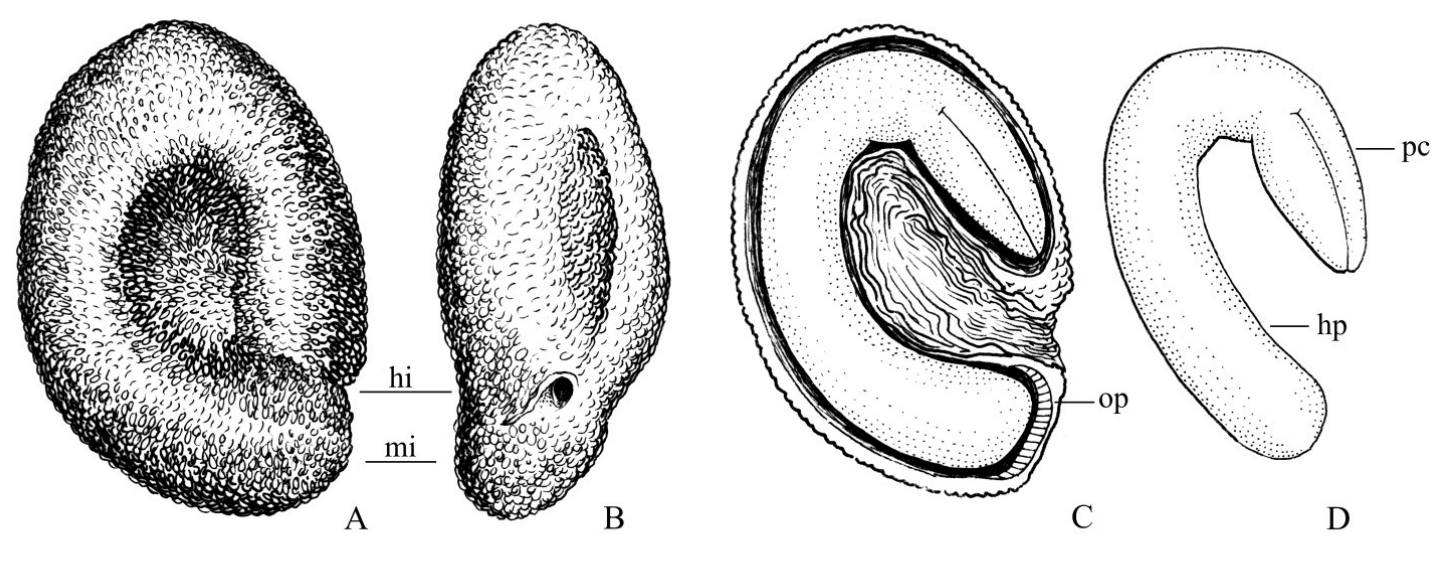

$1 \mathrm{~mm}$

FIGURA 1. Morfologia de semente de Curitiba prismatica. A-B: aspecto externo; C: seção longitudinal; D: morfologia do embrião. (hi: região do hilo; hp: hipocótilo; mi: região da micrópila; op: opérculo micropilar; pc: paracotilédone).

\section{Caracterização morfológica do desenvolvimento} da plântula: germinação das sementes é epígea fanerocotiledonar, e inicia-se no $18^{\circ}$ dia se estendendo até o $65^{\circ}$ dia, considerada rápida segundo $\mathrm{Ng}(1978)$. De acordo com este autor uma germinação rápida de todas as sementes viáveis em um curto período de tempo é uma estratégia bem sucedida, mas ineficaz, pois as plântulas irão competir entre elas. Estas espécies estarão mais vulneráveis à extinção, pois são mais suscetíveis ao ataque de predadores e não possuem um estoque de sementes no solo.

O desenvolvimento da plântula se inicia com a 
abertura do opérculo e uma pequena expansão do hipocótilo nesta região. Após esta expansão, ocorre o desenvolvimento de pêlos na base do hipocótilo e a emissão da radícula, por volta do $18^{\circ}$ dia após a semeadura (Figura 2-A, B). A radícula é densamente pilosa, de coloração creme. O hipocótilo, inicialmente curvo, se expande elevando os paracotilédones ainda presos ao tegumento (Figura 2-C). Após o desprendimento dos cotilédones do tegumento (Figura 2-D), e a abertura e expansão dos mesmos (Figura 2-E), ocorre o surgimento dos eofilos, formando-se a plântula propriamente dita aos 45 dias (Figura 2-F).

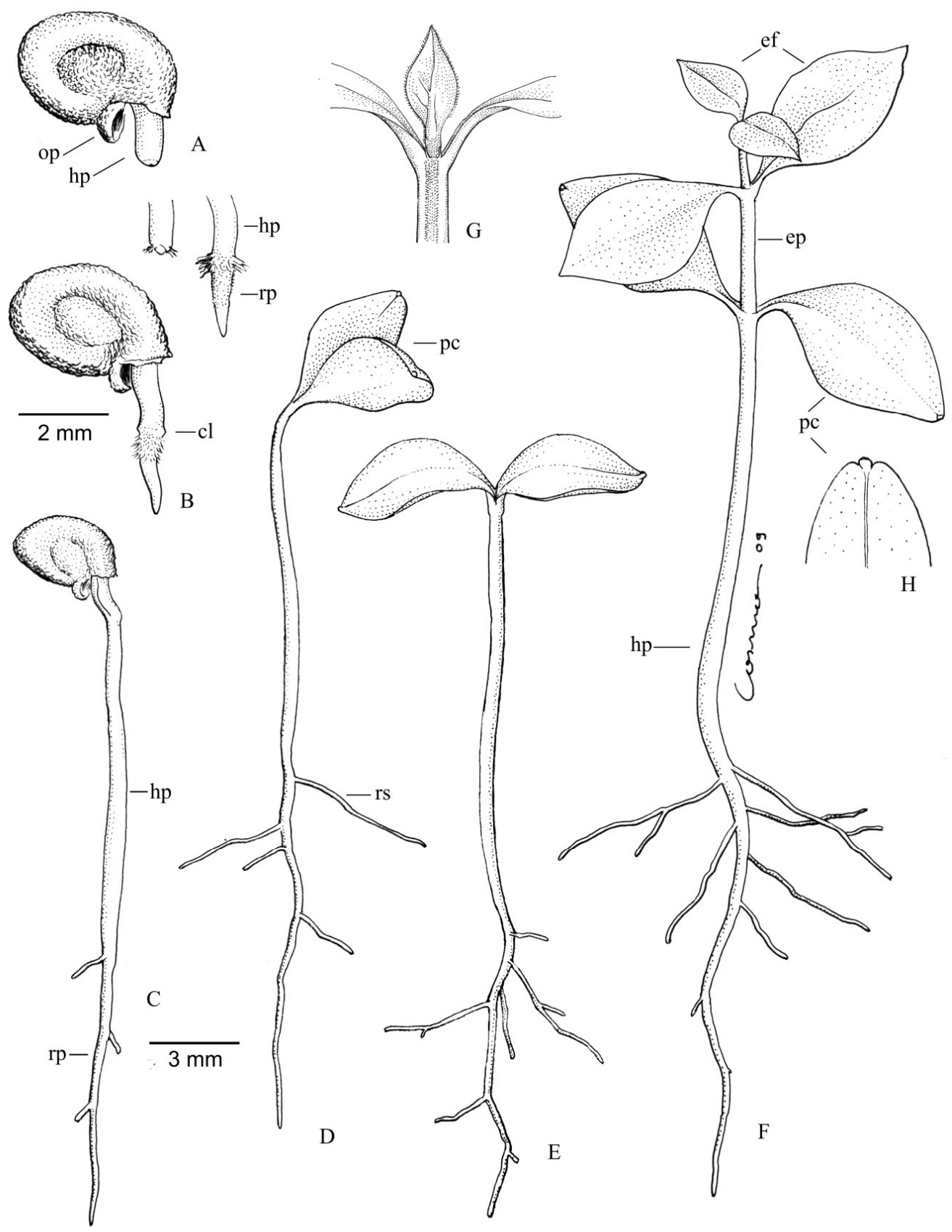

FIGURA 2. Desenvolvimento da plântula de Curitiba prismatica. A-B: emissão do hipocótilo e da raiz primária; C: expansão do hipocótilo e da raiz; D-E: abertura dos paracotilédones; F: desenvolvimento dos eofilos; G: detalhe do nó cotiledonar; H: detalhe do ápice do paracotilédone (cl: colo; ef: eofilo; ep: epicótilo; hp: hipocótilo; op: opérculo micropilar; rp: raiz primária; rs: raiz secundária). 
Os cotilédones são foliáceos, de cor verde-clara, levemente discolores, com margem inteira, nervuras pouco marcadas, superfície lisa, forma ovada, base decurrente e ápice retuso, com uma pequena glândula visível sob lupa (Figura 2-F, H). Vogel (1980) denominou este tipo de cotilédone de paracotilédones de acordo com a sua forma e função. Sementes que apresentam paracotilédones, como C. prismatica possuem pouco ou não apresentam endosperma, pois a função de nutrir a plântula será realizada pelos paracotilédones através da fotossíntese (Ng, 1978; Vogel, 1980). O pecíolo tem cerca de um terço do tamanho da lâmina do paracotilédone.

Os eofilos são opostos cruzados, simples, peciolados, membranáceos e elípticos, com margem inteira, ápice acuminado e base decurrente (Figura 2-F). Possuem glândulas na face abaxial e tricomas ao redor de toda a margem (Figura 2-G). A lâmina verde clara é levemente discolor como nos paracotilédones. A nervura central é marcada na face abaxial e as nervuras secundárias apenas levemente marcadas. As características dos eofilos são muito importantes na identificação de plântulas, pois geralmente o arranjo é específico. Em Myrtaceae quando as folhas adultas são opostas as folhas das plântulas também têm esse arranjo (Vogel, 1980). Outra característica específica é a presença de glândulas nas folhas adultas, que podem ser visualizadas em algumas partes da plântula, como nos cotilédones e eofilos. O hipocótilo possui coloração verde mais claro que as primeiras folhas e paracotilédones, e assim como o epicótilo, possui tricomas.
A plântula de $C$. prismatica é classificada como PEF (fanerocotiledonar, epígea, foliácea) de acordo com Garwood (1996), que classificou as plântulas em cinco tipos: PEF (fanerocotiledonar, epígea, foliácea), PER (fanerocotiledonar, epígea, de reserva), PHR (fanerocotiledonar, hipógea, de reserva), CHR (criptocotiledonar, hipógea, de reserva) e CER (criptocotiledonar, epígea de reserva).

Análises físicas das sementes: para o peso de mil sementes foram obtidos $4,52 \mathrm{~g}(\mathrm{CV}=1,96 \%)$ e para o número de sementes por quilo 220.994. Resultados semelhantes foram encontrados por Lorenzi (1998), que obteve $250.000 \mathrm{~kg}^{-1}$. O grau de umidade das sementes estava em $12,47 \%$.

Germinação das sementes em diferentes temperaturas e substratos: para a porcentagem e índice de velocidade de germinação houve interação entre os substratos e as temperaturas. Entre as temperaturas foi verificado que a $30{ }^{\circ} \mathrm{C}$ a porcentagem de germinação foi menor e estatisticamente diferente das temperaturas 20 ${ }^{\circ} \mathrm{C}$ e $25{ }^{\circ} \mathrm{C}$ (Tabela 1). Como na temperatura de $30^{\circ} \mathrm{C}$ foi registrado a menor porcentagem de germinação (abaixo de $33 \%$ ), não se recomenda para os testes de germinação com esta espécie. Nas temperaturas $20^{\circ} \mathrm{C}$ e $25^{\circ} \mathrm{C}$ não foi verificada diferença entre os substratos, já na temperatura $30{ }^{\circ} \mathrm{C}$ a porcentagem de germinação no substrato papel toalha foi menor comparada ao rolo de papel. Isto pode ter ocorrido porque em temperaturas mais altas o substrato papel tolha resseca com mais facilidade, e o rolo de papel conserva mais a umidade.

TABELA 1. Porcentagem de germinação de sementes de Curitiba prismatica em diferentes substratos e temperaturas.

\begin{tabular}{lcccc}
\hline \multirow{2}{*}{ Substratos } & \multicolumn{3}{c}{ Temperaturas } \\
\cline { 2 - 5 } \cline { 2 - 4 } & $20{ }^{\circ} \mathrm{C}$ & $25^{\circ} \mathrm{C}$ & $30{ }^{\circ} \mathrm{C}$ & Médias (tratamentos) \\
\hline Papel toalha & $85,0 \mathrm{a}$ & $86,3 \mathrm{a}$ & $22,5 \mathrm{~b}$ & $64,6 \mathrm{a}$ \\
Rolo de papel & $86,9 \mathrm{a}$ & $80,6 \mathrm{a}$ & $33,1 \mathrm{a}$ & $66,9 \mathrm{a}$ \\
Areia & $80,0 \mathrm{a}$ & $85,6 \mathrm{a}$ & $26,2 \mathrm{ab}$ & $63,9 \mathrm{a}$ \\
Médias (blocos) & $83,9 \mathrm{~A}$ & $84,2 \mathrm{~A}$ & $27,3 \mathrm{~B}$ & \\
\hline
\end{tabular}

Médias seguidas por letras distintas minúsculas nas colunas e maiúsculas nas linhas diferem entre si pelo teste de Tukey em 5\% de probabilidade. DMS: tratamentos e blocos $(5,39)$ interação $(9,34) \mathrm{CV}: 8,19 \%$.

Com relação ao índice de velocidade de germinação foi observado que na temperatura $25^{\circ} \mathrm{C}$, no substrato rolo de papel foi obtido menor valor em relação ao papel toalha. Nas temperaturas $20{ }^{\circ} \mathrm{C}$ e $30{ }^{\circ} \mathrm{C}$ não houve 
diferença estatística entre os substratos. A temperatura 25 ${ }^{\circ} \mathrm{C}$ propiciou maior IVG, sendo o menor valor observado a $30{ }^{\circ} \mathrm{C}$ (Tabela 2).

Não houve interação entre os substratos e as temperaturas para o tempo médio. Na temperatura de 25 ${ }^{\circ} \mathrm{C}$ foi obtido menor tempo médio em relação às demais temperaturas (Tabela 3). Para os substratos, sementes submetidas ao rolo de papel apresentaram maior tempo médio comparado ao papel toalha. Dessa forma, foi verificado que os melhores resultados para a germinação das sementes de $C$. prismatica foram obtidos com a temperatura $25^{\circ} \mathrm{C}$, nos substratos papel toalha e areia.

TABELA 2. Índice de velocidade de germinação de sementes de Curitiba prismatica em diferentes substratos e temperaturas.

\begin{tabular}{lcccc}
\hline \multirow{2}{*}{ Substratos } & \multicolumn{3}{c}{ Temperaturas } \\
\cline { 2 - 5 } & $20^{\circ} \mathrm{C}$ & $25^{\circ} \mathrm{C}$ & $30{ }^{\circ} \mathrm{C}$ & Médias (tratamentos) \\
\hline Papel toalha & $0,85 \mathrm{a}$ & $1,07 \mathrm{a}$ & $0,22 \mathrm{a}$ & $0,71 \mathrm{a}$ \\
Rolo de papel & $0,82 \mathrm{a}$ & $0,91 \mathrm{~b}$ & $0,31 \mathrm{a}$ & $0,68 \mathrm{a}$ \\
Areia & $0,79 \mathrm{a}$ & $0,99 \mathrm{ab}$ & $0,24 \mathrm{a}$ & $0,67 \mathrm{a}$ \\
Médias (blocos) & $0,82 \mathrm{~B}$ & $0,99 \mathrm{~A}$ & $0,25 \mathrm{C}$ & \\
\hline
\end{tabular}

Médias seguidas por letras distintas minúsculas nas colunas e maiúsculas nas linhas diferem entre si pelo teste de Tukey em 5\% de probabilidade. DMS: tratamentos e blocos $(0,069)$ interação $(0,11) \mathrm{CV}: 9,87 \%$.

TABELA 3. Tempo médio de germinação de sementes de Curitiba prismatica em diferentes substratos e temperaturas.

\begin{tabular}{llccc}
\hline \multirow{2}{*}{ Substratos } & \multicolumn{4}{c}{ Temperaturas } \\
\cline { 2 - 5 } & $20^{\circ} \mathrm{C}$ & $25^{\circ} \mathrm{C}$ & $30{ }^{\circ} \mathrm{C}$ & Médias (tratamentos) \\
\hline Papel toalha & $41,97 \mathrm{a}$ & $35,37 \mathrm{a}$ & $42,83 \mathrm{a}$ & $40,06 \mathrm{~b}$ \\
Rolo de papel & $44,42 \mathrm{a}$ & $38,04 \mathrm{a}$ & $44,42 \mathrm{a}$ & $42,30 \mathrm{a}$ \\
Areia & $42,66 \mathrm{a}$ & $37,35 \mathrm{a}$ & $44,50 \mathrm{a}$ & $41,50 \mathrm{ab}$ \\
Médias (blocos) & $43,02 \mathrm{~A}$ & $36,92 \mathrm{~B}$ & $43,92 \mathrm{~A}$ & \\
\hline
\end{tabular}

Médias seguidas por letras distintas minúsculas nas colunas e maiúsculas nas linhas diferem entre si pelo teste de Tukey em $5 \%$ de probabilidade. DMS: tratamentos e blocos $(1,88)$ interação $(3,26) \mathrm{CV}: 4,51 \%$.

As temperaturas próximas à superfície do solo podem variar bastante entre diferentes ambientes. Grandes clareiras nas florestas tropicais, por exemplo, podem apresentar maiores amplitudes térmicas do que locais sombreados do sub-bosque (Melo et al., 2004). Como C. prismatica é considerada uma espécie secundária, é esperado que suas sementes tenham baixa porcentagem de germinação em temperaturas elevadas $\left(30^{\circ} \mathrm{C}\right)$. Além disso, deve-se considerar que a área de ocorrência da espécie corresponde a um clima subtropical. Rego et al. (2009) também verificaram baixa porcentagem de germinação a $30{ }^{\circ} \mathrm{C}$ para Blepharocalyx salicifolius, espécie da mesma família e grupo ecológico.

A temperatura ideal para a germinação de $C$. prismatica $\left(20\right.$ e $\left.25^{\circ} \mathrm{C}\right)$ também se mostrou adequada para as mirtáceas Acca sellowiana, Blepharocalyx salicifolius, Campomanesia guaz umifolia, Eugenia rostrifolia, Myrcianthes pungens, Psidium cattleyanum e Psidium cuneatum (Santos et al., 2004; Otegui et al., 2007; Rego, 2009).

Neste trabalho, foi verificado que nas temperaturas de $20{ }^{\circ} \mathrm{C}$ e $25^{\circ} \mathrm{C}$ com luz, a germinação das sementes de $C$. prismatica foi alta (acima de $80 \%$ ). Este resultado difere dos encontrados por Lorenzi (1998) que afirmou que a porcentagem de germinação das sementes desta espécie geralmente é baixa. Tal diferença pode ter ocorrido devido às condições de temperatura e luz utilizadas por este autor não foram as ideais para a germinação da 
espécie, visto que a germinação é baixa em temperaturas elevadas e na ausência de luz. Wielewicki et al. (2006) também verificaram altas porcentagens de germinação para espécies da mesma família (Psidium cattleyanum, Eugenia involucrata, Eugenia uniflora e Myrcianthes pungens).

O papel toalha proporcionou altas porcentagens de germinação para as sementes de $C$. prismatica nas temperaturas $20^{\circ} \mathrm{C}$ e $25^{\circ} \mathrm{C}$. Apesar de este substrato estar entre os melhores para a germinação das sementes, precisa ser reumedecido com maior freqüência, já que o processo de germinação da espécie é lento, em média de 70 dias, além de possuir baixa resistência quando disposto em rolos de papel, fato também verificado por (Willan, 1991 e Figliolia e Piña Rodrigues 1995).

Germinação das sementes em diferentes condições de luz: as médias de porcentagem e de índice de velocidade de germinação na luz e no escuro diferiram estatisticamente entre si, sendo que as médias obtidas para a presença de luz apresentaram os maiores valores. Já para o tempo médio não houve diferença estatística entre os tratamentos (Tabela 4). No escuro, a germinação foi baixa (35,6\%). Desta forma, testes de germinação com esta espécie devem ser realizados na presença de luz. Fotoblastismo positivo também foi observado em Acca sellowiana, Myrcianthes pungens e Psidium cattleyanum (Santos et al., 2004).

TABELA 4. Porcentagem, tempo médio (TM) e índice de velocidade de germinação (IVG) de sementes de Curitiba prismatica em diferentes condições de luz.

\begin{tabular}{lccc}
\hline & \% Germinação & IVG & TM \\
\hline Luz & $91,2 \mathrm{~A}$ & $1,57 \mathrm{~A}$ & $25,7 \mathrm{~A}$ \\
Escuro & $35,6 \mathrm{~B}$ & $0,59 \mathrm{~B}$ & $25,2 \mathrm{~A}$ \\
CV\% & 5,96 & 10,69 & 6,07 \\
DMS & 6,55 & 0,20 & 2,73 \\
\hline
\end{tabular}

Médias seguidas por letras distintas nas colunas diferem entre si pelo teste de Turkey em 5\% de probabilidade.

De acordo com estes resultados a espécie seria classificada como fotoblástica positiva. No entanto, de acordo com Klein e Felippe (1991) o fotoblastismo positivo nem sempre é absoluto, pois muitas espécies que se comportam como fotoblásticas positivas apresentam pelo menos alguma germinação no escuro. Em outros casos, embora estatisticamente a espécie possa ser considerada fotoblástica positiva, este caráter é apenas quantitativo, uma vez que tanto na presença como na ausência de luz ocorre considerável germinação de suas sementes, fato observado também para C. prismatica. Klein e Felippe (1991) classificaram estas espécies como fotoblásticas preferenciais.

\section{CONCLUSÕES}

A semente de C. prismatica é exalbuminosa, espiralada com tegumento coriáceo, castanho-escuro. O embrião é do tipo cotiledonar pimentóide, axial, cilíndrico, curvado e de coloração branca.

A plântula de $C$. prismatica é fanerocotiledonar, epígea, foliácea.

As sementes de Curitiba prismatica são fotoblásticas positivas preferenciais, e os maiores valores de porcentagem e índice de velocidade de germinação são obtidos com a temperatura $25^{\circ} \mathrm{C}$, nos substratos papel toalha e areia.

\section{AGRADECIMENTOS}

Ao Engenheiro Florestal Murilo Lacerda Barddal da Companhia Paranaense de Energia (COPEL) por ceder as sementes para a realização deste trabalho.

\section{REFERÊNCIAS}

BARROSO, G.M. Sistemática de angiospermas do Brasil. v.2. Viçosa: UFV, 1984. 377p.

BARROSO, G.M.; MORIM, M.P.; PEIXOTO, A.L.; ICHASO, C.L.F. Frutos e sementes: morfologia aplicada à sistemática de dicotiledôneas. Viçosa: UFV, 1999. 443p.

BORGES, E.E. de L.e.; RENA, A.B. Germinação de sementes In: AGUIAR, I.B. de; PIÑA-RODRIGUES, F.C.M.; FIGLIOLIA, M.B. Sementes florestais tropicais. Brasília: ABRATES, 1993. p.83-135.

BRASIL. Ministério da Agricultura, Pecuária e Abastecimento. Regras para análise de sementes. Ministério da Agricultura, Pecuária e Abastecimento. Secretaria de Defesa Agropecuária. Brasília, DF: Mapa/ ACS, 2009. 395p.

CARVALHO, N.M.; NAKAGAWA, J. Sementes: ciência, tecnologia e produção. Campinas: Fundação Cargill, 1983. $429 \mathrm{p}$. 
FIGLIOLIA, M.B.; OLIVEIRA, E. de C.; PINÃRODRIGUES, F.C.M. Análise de sementes In: AGUIAR, I.B. de; PIÑA-RODRIGUES, F.C.M.; FIGLIOLIA, M.B. Sementes florestais tropicais. Brasília: ABRATES, 1993. p.137-174.

FIGLIOLIA, M.B.; PIÑA-RODRIGUES, F.C.M. Considerações práticas sobre o teste de germinação. In: Manual técnico de sementes florestais. IF Série Registros, São Paulo, n.14, p.45-59, 1995.

GARWOOD, N.C. Functional morphology of tropical tree seedling. In: SWAINE, M.D. The ecology of tropical forest tree seedling. Paris: Unesco, 1996. p.59-129.

GUI FERREIRA, A.; CASSOL, B.; ROSA, S.G.T. da.; SILVEIRA, T.S. da.; STIVAL, A.L.; SILVA, A. A. Germinação de sementes de Asteraceae nativas no Rio Grande do Sul, Brasil. Acta Botânica Brasílica, v.15, n.2, p.231-242. 2001.

KLEIN, A.; FELIPPE, G.M. Efeito da luz na germinação de sementes de ervas invasoras. Pesquisa Agropecuária Brasileira, v.26, n.7, p.955-966, 1991.

KUNIYOSHI, Y.S. Morfologia da semente e da germinação de 25 espécies arbóreas de uma Floresta com Araucaria. 1983. 233f. Dissertação (Mestrado em Ciências Florestais) - Departamento de Engenharia Florestal, Universidade Federal do Paraná, Curitiba, 1983.

LABORIAU, L.G. A germinação das sementes. Washington: Secretaria Geral da Organização dos Estados Americanos, 1983. 174p.

LANDRUM, L.R.; KAWASAKI, M.L. The genera of Myrtaceae in Brazil: an illustrated synoptic treatment and identification keys. Brittonia, v.49, n.4, p.508-536, 1997.

LEGRAND, D.C.; KLEIN, R. Mirtáceas: eugenia. In REITZ, P.R. Flora ilustrada catarinense. Itajaí: Herbário Barbosa Rodrigues, p.46-216, 1969.

LORENZI, H. Árvores Brasileiras: manual de identificação e cultivo de plantas arbóreas nativas do Brasil. v.2. Nova Odessa: Plantarum, 1998. 352p.

MAGUIRE, J.D. Speed of germination aid in selection and evaluation for seedling emergence and vigor. Crop Science, v.2, n.1, p.176-177, 1962.

MARCOS FILHO, J. Fisiologia de sementes de plantas cultivadas. Piracicaba: FEALQ, 2005. 495p.

MELO, M. G.G.; MENDONÇA, M.S.; MENDES, A.M. da $\mathrm{S}$. Análise morfológica de sementes, germinação e plântulas de jatobá (Hymenaea intermedia Ducke var. adenotricha
(Ducke) Lee \& Lang.) (Leguminosae- Caesalpinioideae). Acta Amazonica, v.34, n.1, p.9-14, 2004. http://www. scielo.br/pdf/aa/v34n1/v34n1a02.pdf

NG, F.S.P. Strategies of establishment in Malayan forest trees. In: TOMLINSON, P.B.P.; ZIMMERMANN, M.H. (Ed). Tropical trees as living systems. London: Cambridge University Press, 1978. p.129-162.

OTEGUI, M.; SOROL, C.; FLECK, A.; KLEKAILO, G. Madurez fisiológica, germinación y conservación de semillas de guayabito (Psidium cuneatum Camb.Myrtaceae). Revista Brasileira de Sementes, v.29, n.3, p.160-169, 2007. http://www.scielo.br/pdf/rbs/v29n3/ a19v29n3.pdf

PIÑA-RODRIGUES， F.C.M.; FIGLIOLIA, M.B.; PEIXOTO, M.C. Tecnologia de sementes: Testes de qualidade. In: FERREIRA, A.G.; BORGHETTI, F. Germinação - do básico ao aplicado. Porto Alegre: Artmed, 2004. p. 265-282.

PIÑA-RODRIGUES, F.C.M.; VIEIRA, J.D. Teste de germinação. In: PIÑA-RODRIGUES, F.C.M. Manual de análise de sementes florestais. Campinas: Fundação Cargill, 1988. p. 70-90.

REGO, S.S.; NOGUEIRA, A.C.; KUNIYOSHI, Y.S.; SANTOS, Á.F. dos. Germinação de sementes de Blepharocalyx salicifolius (H.B.K.) Berg. em diferentes substratos e condições de temperaturas, luz e umidade. Revista Brasileira de Sementes, v.31, n.2, p.212-220, 2009. http://www.scielo.br/pdf/rbs/v31n2/v31n2a25.pdf

REGO, S.S.; NOGUEIRA, A.C. KUNIYOSHI, Y.S.; SANTOS, A.F. dos. Caracterização morfológica do fruto, da semente e do desenvolvimento da plântula de Blepharocalyx salicifolius (H.B.K.) Berg. e Myrceugenia gertii Landrum - Myrtaceae. Revista Brasileira de Sementes, v.32, n.3, p.52-60, 2010. http://www.scielo.br/ $\mathrm{pdf} / \mathrm{rbs} / \mathrm{v} 31 \mathrm{n} 2 / \mathrm{v} 31 \mathrm{n} 2 \mathrm{a} 25 . \mathrm{pdf}$

SALYWON, A.M.; LANDRUM, L.R. Curitiba (Myrtaceae): A new genus from the planalto of southern Brazil. Brittonia, v.59, n.4, p.301-307, 2007.

SANTOS, C.M.R. dos.; FERREIRA, A.G.; ÁQUILA, M.E.A. Características de frutos e germinação de sementes de seis espécies de Myrtaceae nativas do Rio Grande do Sul. Ciência Florestal, v.14, n.2, p.13-20, 2004. http:// www.scielo.br/pdf/rbs/v31n2/v31n2a25.pdf

SOUZA, L.A. de. Anatomia do fruto e da semente. Ponta Grossa: UEPG. 2006. 200p.

USBERTI, R. Estudo da germinação de sementes de limão cravo (Citrus reticulata var. austera Hib. 
Swingle): condições de umidade e armazenamento e relações hormonais. 1979. 70f. Dissertação (Mestrado em Fisiologia Vegetal) - Departamento de Fisiologia Vegetal, Universidade Estadual de Campinas, Campinas, 1979.

VIDAL, W.N.; VIDAL, M.R.R. Botânica organografia: quadros sinóticos ilustrados de fanerógamos. Viçosa: UFV, 2003. 124p.

VOGEL, E.F. Seedlings of dicotyledons: structure, development, types: descriptions of 150 woody Malesian taxa. Wageningen: Centre for Publishing and Documentation, $1980.471 \mathrm{p}$.
WILLAN, R.L. Guia para la manipulacíon de semillas forestales con especial referencia a los trópicos. Roma: Estudio FAO Montes - Organizacion de lãs Naciones Unidas para la Agricultura y la Alimentacion, 1991. 502p.

WIELEWICKI.A.P.;LEONHARDT, C.; SCHLINDWEIN, G.; MEDEIROS, A.C. de S. Proposta de padrões de germinação e teor de água para sementes de algumas espécies florestais presentes na região sul do Brasil. Revista Brasileira de Sementes, v.28, n.3, p.191-197, 2006. http:// www.scielo.br/pdf/rbs/v28n3/27.pdf 